
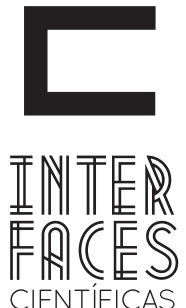

SAÚDE E AMBIENTE

\title{
ANÁLISE QUANTITATIVA DE MASTÓCITOS NA CICATRIZAÇ̃̃ DE FERIDAS TRATADAS COM MEMBRANAS DE COLÁGENO CONTENDO PRÓPOLIS VERMELHA
}

\section{André Luiz Santos Barreto Talita Santos Bastos" \\ Jônatas Almeida Pires "'}

RESUMO
Ricardo Luiz Cavalcanti de Albuquerque Júnior Iv
Juliana Cordeiro Cardoso v
Mastócitos são células do tecido conjuntivo responsáveis pelo início da reação inflamatória e cronificação do processo, e desempenham um papel importante na dinâmica do reparo cicatricial. 0 uso de membranas biológicas naturais ou sintéticas no reparo de feridas dérmicas extensas, por sua vez, tem sido bastante discutido na literatura, especialmente aquelas à base de colágeno, devido à biocompatibilidade e interatividade desse material. A própolis é um produto natural que apresenta atividade anti-inflamatória, podendo contribuir para a reparação cicatricial. A variedade vermelha desse produto, contudo, ainda é pouco estudada, existindo alguns relatos de uma provável ação cicatrizante. Assim, o objetivo deste trabalho foi analisar o efeito da associação de membranas de colágeno à própolis vermelha sobre a população de mastócitos durante o reparo cicatricial por segunda intenção em ratos. Para tanto, foram preparadas membranas de colágeno I extraído de tendão bovino (10-15 $\mu \mathrm{m}$ de espessura) contendo extrato hidroalcóolico de própolis vermelha a
$0,1 \%$. Posteriormente, foram realizadas feridas de $1 \mathrm{~cm}^{2}$ no dorso de 30 ratos Wistar, que foram distribuídos em seis grupos ( $n=5)$ : $G 1$ - animais sem tratamento sacrificados em 7 dias; $\mathrm{G} 2$ - animais tratados com membrana de colágeno sacrificados em 7 dias; G3 - animais tratados com membrana de colágeno contendo própolis vermelha sacrificados em 7 dias; G4 - animais sem tratamento sacrificados em 14 dias; G5 - animais tratados com membrana de colágeno sacrificados em 14 dias; G6 - animais tratados com membrana de colágeno contendo própolis vermelha sacrificados em 14 dias. Os espécimes removidos foram fixados, processados histologicamente e emblocados em parafina e secções histológicas foram coradas em Azul de toluidina. Ao sétimo dia, a população média de mastócitos total e marginal em G1 mostrou-se significativamente menor que em G2 e G3 $(p<0,05)$, mas não houve diferença entre os dois últimos. Ao décimo quarto dia não foi observada diferença estatisticamente significativa entre o G4, G5 e G6 nem na média total de mastócitos, nem nas duas 
regiões estudadas separadamente. Sugere-se que, em ratos, o uso de membranas bioativas de colágeno, independentemente de conter ou não própolis vermelha sob a forma de extrato hidroalcoólico a $0,1 \%$, pode reduzir a desgranulação de mastócitos aos sete dias de cicatrização de feridas abertas, mas não influencia a população desta célula imunocompetente nas fases finais (14 dias) do reparo.

\section{PALAVRAS-CHAVE}

Inflamação. Mastócitos. Própolis Vermelha.

\section{ABSTRACT}

Mast cells are connective tissue cells responsible for initiating the inflammatory reaction and chronicity of the process, and play an important role in the dynamics of the repair scar. The use of natural or synthetic biological membranes in the repair of extensive dermal wounds, in turn, has been widely discussed in the literature, particularly those based on collagen, due to biocompatibility and interactivity of these materials. Propolis is a natural product that presents anti-inflammatory properties, so that it could be useful to the repair scar. The red variety of this product, however, is still less studied, although there are some reports of a probable healing action. Thus, the objective of this study was to analyze the effect of the combination of collagen membranes to red propolis on the mast cells population during repair scar by second intention in rats. For this purpose, membranes were prepared from collagen extracted from bovine tendon (10-15 $\mu \mathrm{m}$ thick) containing hydroalcoholic extract of red propolis to $0.1 \%$. Subsequently, $1 \mathrm{~cm} 2$ standard-sized wounds were performed in th back of 30 Wistar rats, which were divided into six groups $(n=5)$ : $G 1$ - untreated animals sacrificed at 7 days; G2 - animals treated with collagen membrane sacrificed at 7 days; G3 - animals treated with collagen membrane containing red propolis sacrificed at 7 days; G4 - untreated animals sacrificed at 14 days; G5 - animals treated with collagen membrane sacrificed at 14 days; and G6 - animals treated with collagen membrane containing red propolis sacrificed at 14 days. The removed specimens were fixed, histologically processed and embedded in paraffin and histological sections were stained with toluidine blue. On the seventh day, the average population of mast cells in total and marginal G1 was significantly lower than in G2 and G3 $(P<0.05)$, but there was no difference between these last two groups. At the fourteenth day, it was not verified any statistically significant difference in the mean of mast cells among the three groups. These data suggest that, in mice, the use of bioactive collagen membranes, containing or not $0.1 \%$ hydroalcoholic extracts of red propolis, can reduce the degranulation of mast cells after seven days of healing of wounds, but has no effect on this population of immunocompetent cell in the final stages (14 days) repair.

\section{KEYWORDS}

Inflammation. Mast Cells. Red Propolis.

\section{RESUMEN}

Los mastocitos son células del tejido conectivo responsables por el inicio de la reacción inflamatoria y la cronicidad del proceso y juegan un papel impor- tante en la dinámica de la reparación cicatricial. El uso de membranas biológicas naturales o sintéticas en la reparación de heridas dérmicas extensas, a su 
vez, ha sido ampliamente discutido en la literatura, especialmente los basados en colágeno, debido a la biocompatibilidad y la interacción del material. El própolis es un producto natural que tiene actividad antiinflamatoria, que puede contribuir a la reparación cicatricial. La variedad roja de este producto, sin embargo, ha sido poco estudiada, y hay algunos informes de una probable acción cicatrizante. De esta manera, el objetivo de este estudio fue analizar el efecto de la combinación de membranas de colágeno y própolis rojo en la población de mastócitos durante la reparación cicatricial por segunda intención en ratos. Para este propósito, las membranas se prepararon a partir de colágeno I extraído de tendón de bovino (10-15 $\mu \mathrm{m}$ de espesor) que contiene extracto hidroalcohólico de própolis a $0,1 \%$. Posteriormente, hicieron heridas de $1 \mathrm{~cm} 2$ sobre el dorso de 30 ratones Wistar, que se dividieron en seis grupos ( $n=5)$ : $G 1$ - animales no tratados sacrificados a los 7 días, G2 - animales tratados con membrana de colágeno sacrificados a los 7 días; G3 - animales tratados con membrana de colágeno contieniendo própolis roja sacrificados después de 7 días; G4 - los animales no tratados sacrificados a los 14 días; G5 - animales tratados con membrana

\section{INTRODUÇÃ̃}

A resposta inflamatória corresponde a uma reação dos tecidos vascularizados a agentes agressores, caracterizados morfologicamente pela saída de líquidos e de células do sangue para o interstício, e resulta em alterações teciduais classificadas como aguda e crônica. A inflamação aguda é a resposta imediata e precoce caracterizada por emigração de leucócitos em grande quantidade, predominantemente de neutrófilos, cujas principais manifestações clínicas são rubor, calor, dor e edema. A inflamação crônica, por sua vez, é considerada de duração prolongada - semanas ou meses - e tem como uma das principais características a lesão tecidual continuada, com infiltrações de colágeno sacrificado a los 14 días; G6 - animales tratados con membrana de colágeno contieniendo própolis roja sacrificados en 14 días. Las muestras extraídas se fijaron, se procesaron y se agruparon en parafina, se hicieron cortes histológicos y se tiñeron con azul de toluidina. En el séptimo día, el promedio de la población de mastocitos en G1 total y marginal fue significativamente menor que en el G2 y G3 ( $p$ $<0,05)$, pero no hubo diferencias entre los dos últimos. En el día catorce, no hubo diferencias estadísticamente significativas entre el G4, G5 y G6 ni en el promedio total de mastócitos, ni en las dos regiones estudiadas por separado. Se sugiere que, en ratones, la utilización de membranas de colágeno bioactivos, independiente o no de contener própolis rojo en forma de extracto hidroalcohólico 0,1\%, puede reducir la degranulación de los mastocitos después de siete días de cicatrización de heridas abiertas, pero no tiene efecto sobre la población de esta célula inmunocompetente en etapas finales (14 días) de reparación.

\section{PALABRAS CLAVE \\ Inflamación, Mastócitos, Própolis Rojo}

de células como macrófagos, linfócitos, plasmócitos (DIEGELMANN; EVANS, 2004).

A resposta inflamatória está estreitamente interligada ao processo de reparação tecidual e serve para destruir, diluir ou encerrar o agente agressor; por sua vez, põe em movimento uma série de eventos que, tanto quanto possível, cicatrizam e reconstituem o tecido danificado. Contudo, a inflamação e a reparação, quando não bem-coordenadas, são potencialmente lesivas (NETTO et al., 2007).

Os mastócitos são formados a partir das células multipotentes hematopoiéticas e expressam CD13, 
CD34 e CD 117 (GILIFILAN; TRACZYK, 2006), sendo os seus precursores AA4+/ BGD6+ (JAMUR et al., 2005), originando-se na medula óssea.

Mastócitos são células provenientes do tecido conjuntivo que auxiliam no mecanismo de defesa imunológica, estando envolvidos em reações inflamatórias, reações de hipersensibilidade, respostas imunes locais, tais como a expulsão de alguns patógenos (KRISHNASWAMY et al., 2006).

A migração dos mastócitos se dá através do sistema circulatório sanguíneo para os tecidos periféricos, sendo o local de amadurecimento através de estímulos do microambiente em questão formando o mastócito maduro (GALLI et al., 2005). A morfologia dos mastócitos maduros é caracterizada por células alongadas, apresentando citoplasma repletos de grânulos que se coram metacromicamente por corantes básicos, como o azul de toluidina. Ultraestruturalmente apresentam microvilos em sua membrana plasmática, núcleo centralizado, sendo este arredondado, contendo dois ou mais nucléolos (DVAROK, 2005).

Tais mastócitos são de grande relevância funcional para o sistema imunológico devido à sua capacidade de produção de mediares químicos, sendo responsáveis pela síntese e liberação de inúmeros produtos farmacologicamente ativos, tais como os fatores pré-formadores, sendo esses formados por substâncias que participam da imunidade, da hematopoiese, e do remodelamento dos tecidos; fatores neo-formados e os fatores neo-sintetizados, que são os fatores estimuladores de granulócitos / macrófagos (TRIVELLATO et al., 2004; RIVERA; GILFILLAN, 2006).

Os mastócitos apresentam funções relevantes na gênese do tecido conjuntivo, compreendendo a liberação de mediadores que estimulam a propagação de fibroblastos e síntese de colágeno (GARBUZENKO et al., 2002; PEREIRA et al., 2007). Estudos demonstram a relação entre a presença de mastócitos e fi- broses na pele (GARBUZENKO et al., 2002).

Quando ativados, os mastócitos aumentam em número, tamanho e granulosidade (BEZERRA et al., 2003). Desta forma, a relação da população de mastócitos, inflamação e reparo tem sido extensivamente pesquisada na literatura, especialmente em modelo animal (MUSSED et al., 2003; RIBEIRO, 2006; NETTO et al., 2007).

Existem vários relatos na literatura acerca do uso de produtos naturais no combate à inflamação e consequente melhoria do processo de reparo, a exemplo da própolis (CASTALDO, CASPASSO, 2002; SEMENOFF et al., 2007). Entre os efeitos pró-cicatrizantes das diversas variedades de própolis, destaca-se um provável potencial anti-inflamatório (GRÉGIO et al., 2005; RAMOS; MIRANDA, 2007). No entanto, apesar de muitos estudos virem sendo realizados com própolis verde, ainda são poucos os trabalhos que enfoquem as propriedades biológicas da variedade vermelha da própolis brasileira (TRUSHEVA et al., 2006).

Assim, este trabalho objetivou estudar o efeito do uso de filmes de colágeno contendo própolis vermelha sobre a população de mastócitos durante o processo cicatricial por segunda intenção em ratos. 


\section{MATERIAL E MÉTODOS}

\subsection{OBTENÇÃO DOS EXTRATOS}

A obtenção dos extratos de própolis foi realizada conforme a metodologia aplicada por PARK et al. (1998) modificada. Foi usado $1 \mathrm{~g}$ da amostra de própolis, passando por um processo de trituração e homogeneização e em seguida foram adicionados 100

\subsection{CONFECÇ̃̃O DAS MEMBRANAS}

O colágeno tipo I foi obtido de tendão bovino através de tratamento com NaCl, ácido acético 0,5 mol/L e pepsina, segundo método descrito por CARDOSO (2005).

0 extrato seco de própolis foi solubilizado em propilenoglicol 400 (PEG400), o qual serviu como co-solvente, uma vez que a própolis não dissolve em água, e como plastificante. Foi preparada uma solução de PEG400 com concentração de própolis igual a 0,5\%.

Para confecção das membranas, foi utilizada uma dispersão aquosa a 1\% de polímero (colágeno), 0,2\% de plastificante contendo a própolis. A concentração

\subsection{PROCEDIMENTOS CIRÚRGICOS E FORMAÇÃO DE GRUPOS - ES- TUDO PRÉ-CĹNIICO}

Após aprovação do Comitê de Ética em Pesquisa, os ensaios pré-clínicos foram conduzidos de acordo com os padrões éticos exigidos. Para o procedimento cirúrgico foi utilizado um total de 30 ratos machos Wistar $(200 \pm 50 \mathrm{~g})$ mantidos em gaiolas com cama de maravalha, trocadas diariamente, mantidos à temperatura controlada de $22^{\circ} \mathrm{C}$, em regime de luz com ciclo claro-escuro de $12 \mathrm{~h}$, recebendo água ad libitum e dieta padrão Labina ${ }^{\circledR}$ (Purina, São Paulo, Brasil). A confecção das feridas foi realizada sob anestesia geral, com injeção intraperitoneal de tribromoetanol 2,5\%. 0 dorso dos animais foi tricotomizado e a $\mathrm{ml}$ de solução hidroalcóolica $70 \%$. A extração foi efetuada à temperatura ambiente, por 24 horas. Após a extração, a amostra foi filtrada e o solvente rotaevaporado. 0 pó obtido foi armazenado em tubo de ensaio estéril com rosca e mantido em refrigerador.

final no filme após evaporação do solvente foi de $20 \%$ de plastificante em relação à massa seca do polímero e 0,1\% de própolis.

Filmes contendo apenas o polímero e o plastificante também foram preparados. Os filmes foram obtidos através de "Casting process" que consiste em verter a dispersão aquosa do polímero em suportes de polietileno. Estes suportes foram colocados em capela de exaustão e o solvente foi evaporado. Após esta etapa, os filmes foram retirados do suporte, cortados na dimensão de $2 \times 2 \mathrm{~cm}$. A esterilização foi feita utilizando radiação Ultravioleta (raios UV), por um período de 20 minutos.

antissepsia foi efetuada com iodopovidona tópico a $1 \%$. Foram então realizadas feridas cirúrgicas padronizadas em $1 \mathrm{~cm}^{2}$. A profundidade foi determinada através da penetração da parte ativa da lâmina do bisturi em torno de $5,0 \mathrm{~mm}$. Não foi realizada sutura das feridas. Os animais foram então subdivididos nos seguintes grupos $(n=5)$ : $G 1$ - animais sem tratamento sacrificados ao sétimo dia; G2 - animais tratados com membrana de colágeno sacrificados ao sétimo dia; G3 - animais tratados com membrana de colágeno contendo própolis vermelha sacrificados ao sétimo dia; G4 - animais sem tratamento sacri- 
ficados ao décimo quarto dia; G5 - animais tratados com membrana de colágeno sacrificados ao décimo quarto dia; G6 - animais tratados com membrana de colágeno contendo própolis vermelha sacrificados ao décimo quarto dia. Para o sacrifício, os animais foram submetidos à nova administração de anestésico em quantidade três vezes maior àquela utilizada

\subsection{PROCEDIMENTOS HISTOLÓGICOS}

Decorrido o período de 24 horas para a fixação, as peças foram seccionadas transversalmente, desidratadas em álcool, diafanizadas em xilol e incluídas em parafina sob a forma de blocos. Os blocos foram montados no micrótomo e obtidos cortes com $5 \mu \mathrm{m}$ de espessura. De cada animal foi confeccionada uma lâmina, a qual foi submetida à coloração pelo azul de

\section{ANÁLISE ESTATÍSTICA}

Os dados obtidos foram tabulados e analisados para verificar a possível existência de diferenças significativas entre o número médio de células de mastócitos, conforme para anestesia; posteriormente, foi realizada a remoção dos espécimes equivalentes à área cicatricial.

Ressalta-se que, antes da realização dos procedimentos cirúrgicos, o projeto de pesquisa foi submetido e aprovado pelo Comitê de Ética em Pesquisa com Animais.

toluidina a $0,2 \%$, de acordo com a fórmula citada por Cavalcanti (1989). Os cortes foram observados em um microscópio de luz ZEISS, AXIOLAB em aumento aproximado de $100 \mathrm{X}$, onde foram contadas as células marcadas em violeta (interpretadas como mastócitos) em toda a área da ferida cirúrgica, envolvendo ainda $5 \mathrm{~mm}$ além de suas margens e base.

o tempo de sacrifício. Utilizou-se o teste de Kruskal-Wallis para identificação de diferenças estatisticamente significativas entre os grupos, seguida do teste de Dunn.

\section{RESULTADOS}

No presente estudo, os mastócitos foram identificados por sua coloração violeta metacromática, e exibiram, de forma geral, morfologia arredondada e, ocasionalmente, alongada, distribuídos nas margens e na profundidade da zona de reparo, especialmente em posição perivascular e perineural (figura 1). Em todos os casos analisados, os mastócitos mostraram-se mais numerosos nas margens da área de reparo cicatricial que na profundidade (base) (figura 2).

Ao sétimo dia de experimento, a população média de mastócitos nos animais do grupo G1 mostrou-se significativamente menor que nos grupos

experimentais $G 2$ e $G 3(p<0,05)$. No entanto, não houve diferença entre os dois últimos. Individualizando as duas regiões da zona de reparo estudadas, verificou-se que, na porção marginal, havia similarmente diferença significativa na média de mastócitos entre $G 1$ e $G 2(p<0,05)$. Ao décimo quarto dia, por sua vez, não foi observada diferença estatisticamente significativa entre o grupo controle (G4) e os grupos experimentais G5 e G6 nem na média total de mastócitos, nem nas duas regiões estudadas separadamente. Adicionalmente, os grupos experimentais também não mostraram diferenças significativas quando comparados entre si (tabela 1 ). 
Figura 1. Em (A) observam-se mastócitos metacromáticos (violetas) na profundidade da área de reparo cicatricial (G3) exibindo morfologia ovalada (seta) e alongada (seta pontilhada). Em (B) evidenciam-se mastócitos assumindo disposição periférica a uma fibra nervosa (FbN) (Azul de Toluidina, 100X).
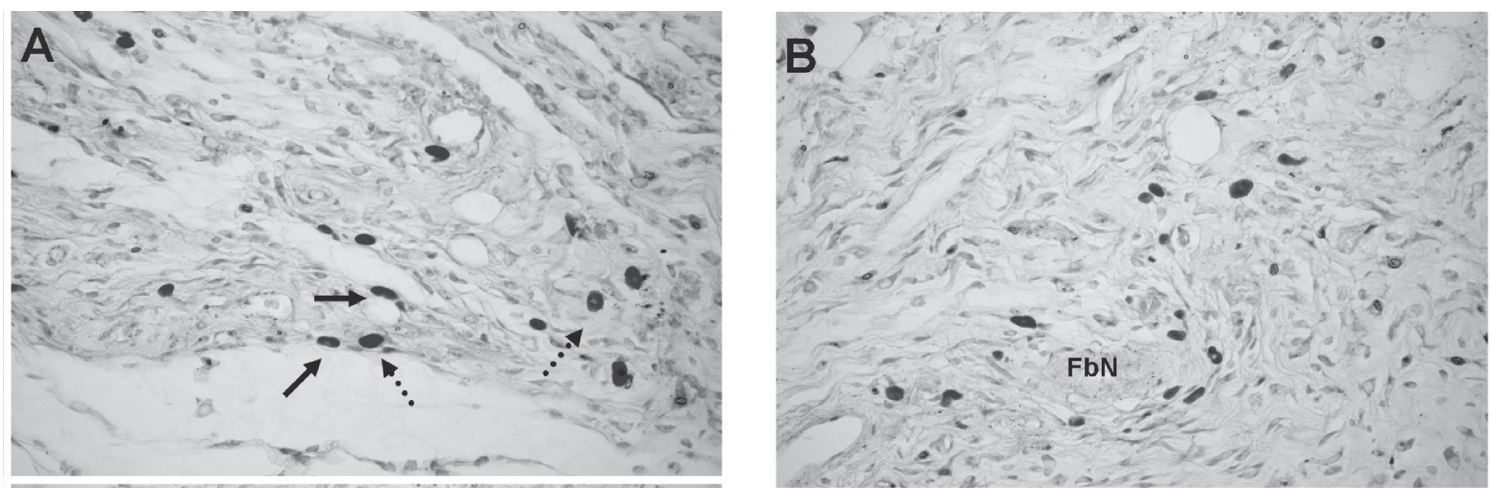

Figura 2. Distribuição dos valores médios da população de mastócitos entre os grupos estudados, mostrando que tanto em 7 quanto 14 dias, havia predomínio destas células nas margens da área de reparo cicatricial, independente do tratamento adotado.

- grupo controle 䍖 grupo membrana $\square$ grupo membrana própolis

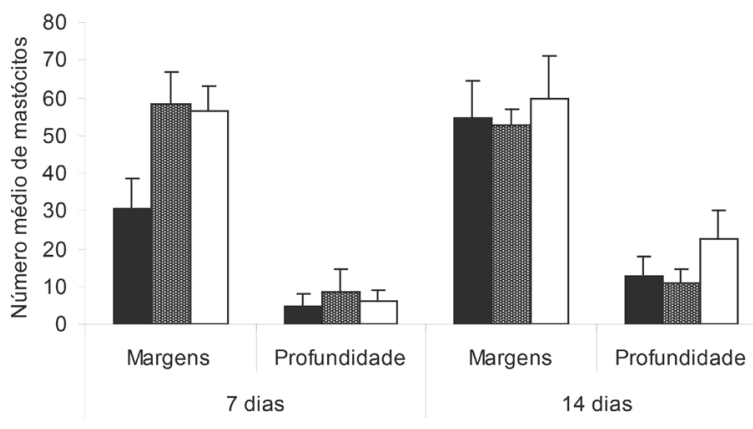

Tabela 1. Distribuição dos valores médios de mastócitos nas margens e profundidade da área de reparo cicatricial nos diversos grupos sacrificados ao sétimo dia após os procedimentos cirúrgicos.

\begin{tabular}{|c|l|l|l|l|}
\hline \multicolumn{2}{|c|}{ Grupos } & \multicolumn{1}{c|}{ Margens } & \multicolumn{1}{c|}{ Profundidade } & \multicolumn{1}{c|}{ Total } \\
\hline \multirow{3}{*}{7 dias } & G1 & $30,4+-8,23^{\text {a,b,e }}$ & $4,8+-7,1$ & $34,9+-9,43^{c, d}$ \\
\cline { 2 - 5 } & $G 2$ & $58,25+-8,42^{\mathrm{a}}$ & $8,5+-6,13$ & $68,25+-12,81^{\mathrm{c}}$ \\
\cline { 2 - 5 } & $\mathrm{G} 3$ & $56,29+-6,7^{\mathrm{b}}$ & $6,0+-2,82$ & $62,25+-8,05^{\mathrm{d}}$ \\
\hline \multirow{3}{*}{14 dias } & $\mathrm{G} 4$ & $54,8+-9,46^{\mathrm{e}}$ & $12,49+-5,62$ & $65,1+-12,88$ \\
\cline { 2 - 5 } & $\mathrm{G} 5$ & $52,5+-9,43$ & $11,0+-3,55$ & $63,5+-5,56$ \\
\cline { 2 - 5 } & $\mathrm{G} 6$ & $59,65+-11,29$ & $82,4+-14,85$ \\
\hline
\end{tabular}




\section{DISCUSSÃO}

Tem sido cada vez mais crescente o número de investigações sobre a importância dos mastócitos em diversos processos fisiopatológicos, especialmente a cicatrização (NETTO et al., 2007). Numerosos modelos experimentais vêm sendo desenvolvidos a fim de estudar as múltiplas funções dos mastócitos in vivo (GALLI, 2000) e in vitro, muitas vezes com emprego de técnicas avançadas (KIRSHENBAUM, 2000).

Os eventos iniciais do processo de reparo estão voltados para o recrutamento em massa de leucócitos fagócitos, especialmente macrófagos, para o sítio de injúria. Este fenômeno é decorrente da ação de mediadores oriundos da desgranulação de mastócitos, o que empresta a esta população celular grande relevância na fase inflamatória da cicatrização (BALBINO et al., 2005).

Contudo, a despeito da reconhecida importância dos mastócitos durante as fases mais precoces da cicatrização (fase inflamatória), tem sido sugerido que, em processos cicatriciais por segunda intenção, pode haver persistência da fase aguda por até uma semana, sugerindo manutenção de atividade quimiotática neste período (RIBEIRO, 2006). Posto que os mastócitos sejam células relacionadas com a iniciação, a manutenção e a amplificação da resposta inflamatória e, quando ativados, liberam, por desgranulação, potentes mediadores, que são capazes de induzir a vasodilatação e aumento da permeabilidade vascular (LOGAN, ODEMUYIWA, MOQBEL, 2003), especula-se a possibilidade de desempenharem algum papel na dinâmica desta persistência.

O significado da distribuição dos mastócitos nos compartimentos teciduais está relacionado com o potencial que os mediadores químicos possuem de influenciar as células circunvizinhas, com efeitos tóxicos, estimulador ou inibidor. Utiliza-se o termo desgranulação para se caracterizar a secreção de proteínas dos grânulos ou vesículas intracelulares pelos mastócitos (LIMA et al., 2005).
Diversos trabalhos são encontrados na literatura demonstrando os efeitos de variados agentes de natureza física e química sobre a população de mastócitos (BEZERRA et al., 2003; LIMA et al., 2005). No entanto, são poucos os estudos a respeito dos efeitos da associação entre fimes bioativos (membranas) de colágeno contendo extrato de própolis vermelha.

A desgranulação de mastócitos pôde ser facilmente identificada em investigações científicas prévias por meio da técnica histoquímica do azul de toluidina (NETTO et al., 2007). O presente estudo corrobora estes dados, haja vista que os mastócitos foram bem marcados, e destacados do tecido e células adjacentes, por meio deste método de coloração.

Neste estudo, o número médio de mastócitos foi estatisticamente menor no grupo controle sacrificado sete dias após os procedimentos de confecções das feridas do que nos grupos experimentais (membrana e membrana/própolis), sugerindo que ambas as formas de tratamento aplicado pareceram influenciar a população destas células.

É sugerido que o menor número de mastócitos identificados pelo azul de toluidina poderia estar relacionado à maior desgranulação destas células, uma vez que o corante se impregna nos grânulos dessas células (RIBEIRO , 2006). Assim, os resultados deste estudo parecem sugerir que no grupo controle (G1) pode ter ocorrido persistência de estímulos capazes de promover desgranulação mastocitária. A identificação de infiltração neutrofílica mais intensa neste grupo, quando comparado aos demais (dados não mostrados), parece corroborar este achado.

Por outro lado, não houve diferença significativa entre os grupos experimentais $\mathrm{G} 2$ e $\mathrm{G} 3$, sugerindo que o uso da membrana de colágeno, e não a própolis vermelha, parece ter sido o fator diferencial na dinâmica da desgranulação mastocitária. 
Em virtude de suas propriedades bioativas, o colágeno, sob diversas formas, vem sendo utilizado como adjuvante no reparo de injúrias físico-químicas (BERNALES et al., 2004, CHENGCAN et al, 2006). Além disso, o potencial de interação da matriz de colágeno acelular com células circunjacentes, a ponto de induzir nestas últimas alterações morfo-estruturais, já foi demonstrado na literatura (CHEN et al, 2000; ELLIOTT et al., 2003).

No entanto, apesar de apresentar numerosas características biomodulatórias, não tem sido relatada na literatura qualquer associação entre o colágeno e atividade antiinflamatória (DIELGEMANN; EVANS, 2004), de modo que a estimulação mastocitária reduzida nos grupos tratados com membrana não parece estar associada à composição físico-química do biofilme, mas sim à proteção mecânica da ferida, o que sabidamente reduz a contaminação microbiana e facilita a instalação e completude do reparo cicatricial.

Deve ser destacado que, neste estudo, a incorporação de extrato hidroalcóolico de própolis vermelha não influenciou a população de mastócitos, e consequente liberação de mediadores vasoativos, ao $7^{\circ}$ dia do experimento. Contudo, estudos prévios demonstram que extratos etanólicos de própolis verde aumentaram a liberação de histamina por mastócitos (FULIANG et al., 2005; ORSI et al., 2005). Dois fatores podem ter contribuído para essa aparente divergência nos resultados. Primeiro, a variedade da própolis usadas nas mencionadas investigações foi a verde, que segundo tem características bastante distintas da variedade vermelha, usada neste experimento (TRUSHEVA et al., 2006). Segundo, o resultado negativo pode ter sido reflexo da baixa concentração testada (apenas 0,1\%). Assim, são necessários estudos posteriores comparando as duas variedades de própolis, e em concentrações maiores, para elucidar melhor esta questão.

Ao $14^{\circ}$ dia, não houve diferença estatisticamente significativa entre nenhum dos grupos testados. Esses achados vêm corroborar a premissa de que mastócitos são células imunologicamente ativas na fase inflamatória e início da fase proliferativa do reparo, mas não nas fases tardias, onde a quimiotaxia e alterações vasculares cedem espaço para fenômenos de deposição colagênica, contração da ferida e remodelação da cicatriz (BALBINO et al., 2005; RIBEIRO, 2006).

De especial interesse foi a observação de mastócitos, independentemente do grupo ou do tempo do experimento, acumulavam-se especialmente nas margens da lesão, em detrimento da sua base profunda, e que, de forma geral, se dispunham em "coleções" ou "aglomerados" celulares. Não foram identificados mastócitos na zona ativa de reparação propriamente dita. Essa disposição particular pode refletir o fato de que a ação mediadora mastocitária se dá sobre vasos e nervos residuais periféricos à zona de injúria (DIEGELMANN; EVANS, 2004; BALBINO et al., 2005), e que talvez esta distribuição arquitetural tenda a se manter mesmo nas fases mais tardias do reparo. Assim, estudos futuros, efetuados em longo prazo, são requeridos para verificar se ocorre ou não neste padrão arquitetural após a fase de remodelação do colágeno e completa maturação da cicatriz.

\section{CONCLUSÃO}

Baseado nos achados deste estudo, sugere-se que o uso de membranas bioativas de colágeno, independentemente de conter ou não própolis vermelha sob a forma de extrato hidroalcoólico a $0,1 \%$, pode reduzir a desgranulação de mastócitos aos sete dias de cicatrização de feridas abertas, mas não influencia a população desta célula imunocompetente nas fases finais (14 dias) do reparo. 


\section{REFERÊNCIAS}

BALBINO, C.A.; PEDREIRA, L.M.; CURI, R. Mecanismos envolvidos na cicatrização: uma revisão. Revista Brasileira de Ciências Farmacêuticas. v.41, n.1, 2005.

BERNALES, D. M.; CARIDE, F.; LEWIS, A.; MARTIN, L. Membranas de colágeno polimerizado: consideraciones sobre su uso en técnicas de regeneración tissular y ósea guiadas. Rev Cubana Invest Biomed.,v.23, n.2, p.65-74, 2004.

BEZERRA, H.L; RIZZO, L.V; YUY, M.C.Z; FREITAS, D. Avaliação da resposta terapêutica nas alergias oculares por meio da citologia esfoliativa. Arq Bras Oftalmol, v.66, p.595-598, 2003.

CARDOSO, S.C. Estimulação elétrica, tipo de desossa e taxas de resfriamento da carne bovina (MM. Longissimus lumborum e Semitendinosus): Efeitos em características físicas, físico-químicas, sensoriais e bacteriológicas. Tese (Doutorado). Faculdade de Engenharia de Alimentos, UNICAMP, Campinas, 2005.

CASTALDO S.; CAPASSO F. Propolis, an old remedy used in modern medicine. Fitoterapia, v.73, p.S1-S6, 2007.

CHEN, C.S.; OSTUNI, E.; WHITESIDES, G.M.; INGBER, D.E. Using self-assembled monolayers to pattern ECM proteins and cells on substrates. Methods Mol. Biol., v.139, p.209-219, 2000.

CHENGCAN, Y.; PING, Y.; HAO, W.; ZHENGANG, Z. Acceleration of wound healing in traumatic ulcers by absorbable collagen sponge containing recombinant basic fibroblast growth factor. Biomed Mater. v.1, p.33-37, 2006.

DIEGELMANN, R.F.; EVANS, C.M. Wound healing an overview of acute, fibrotic and delayed healing. Fron- tiers in Bioscience, v..9, p.283-289, 2004.

DVORAK A. M (2005) Ultrastructure of mast cells and basophils. In Dvorak AM, ed. Chemical Immunology and Allergy, Vol. 85. Ring J, Adorini L, Berek C, Blaser K, Capron M, Denburg J, Holgate S, Marone G, Saito H, series eds. Basel, Karger, 1-351

ELLIOTT, J.T.; TONA, A.; WOODWARD, J.T.; JONES, P.L.; PLANT, A.L. Thin Films of Collagen Affect Smooth Muscle Cell Morphology. Langmuir, v.19, n.5, p.15061514, 2003.

FULIANG, H.U; HEPBURN, H.R; YINGHUA, L; CHEN, M; RADLOFF, S.E; DAYA, S. Effects of ethanol and water extracts of própolis (bee glue) on acute inflammatory animal models. Journal Ethnopharmacology, v.100, p.276-283, 2005.

GARBUZENKO E, NAGLER A, PICKHOLTZ D, GILLERY P, REICH R, MAQUART FX, et al. Human mast cells stimulate fibroblast proliferation, collage synthesis and lattice contraction: a direct role for mast cells skin fibrosis. Clin Exp Allergy. v.32, p.237-246, 2002.

GALLI, S. J. Mast cells and basophils. Curr Opin Hematol, v.7, p.32-39, 2000.

GALLI, S.J.; NAKAE, S.; TSAI, M.; Mast cells in the development of adaptive immune responses. Natury Imunology, v.6, n.2, p.135-142, 2005.

GRÉGIO, A.M. T.; LIMA, A.A.S.; RIBAS, M.O.; BARBOSA, A.P.M.; PEREIRA, A.C.P.; KOIKE, F; REPEKE, C.E.P. Efeito da Própolis melífera sobre o processo de reparo de lesões ulceradas na mucosa bucal de ratos. Estud. Biolog., v.27, n.58, 2005.

JAMUR, M. C. Mastócitos. In: Carvalho, H. F.; Collares-Buzato, C. B. (Org.). Células: uma abordagem multidisciplinar. Barueri: Ed. Manole, 2005. p. 382-391. 
KIRSHENBAUM, A.S.; SEMERE, T.; WOROBEC, A.S.; SCOTT, L.M. Mastocitosis cutánea. Exp. Hematol. v. 28, n.19, p.140-147, 2000.

KRISHNASWAMY, G.; AJITAWI, O.; CHI D.S. The human mast cell: an overview. Methods Mol Biol, v.315, p.1314, 2006.

LIMA, A.A.S.; GRÉGIO, A. M. T.; FRANÇA, B. H. S.; MACHADO, M. A. N.; IGNÁCIO, A. S.; CENTURIÓN, M. M. População de mastócitos em ulcerações bucais de ratos tratadas com extrato etanólico de própolis. Rev. Bras. Patol Oral., v.4, n.3, p.2-9, 2005.

LOGAN, M.R.; ODEMUYIWA, S.O.; MOQBEL, R. Understanding exocytosis in immune and inflammatory cells: the molecular basis of mediator secretion. J Allergy Clin Immunol, v.111, n.5, p.923-932, 2003.

MUSSED, R.L.O.; SILVA, E.S.; COSTA, A.M.A.; MANDARIM DE LACERDA, C.A. Mast cells in tissue response to dentistry materials: an adhesive resin, a calcium hydroxide and a glass ionomer cemen. J.Cell.Mol. Med., v.7, n.2, p.171-178, 2003.

NETTO, B.D.M.; SCHWEGLER, A.C.; LIMA, A.A.S.; SCUR, E.M. Avaliação de mastócitos da mucosa intestinal inflamada de ratos submetidos à ingestão de ácidos graxos insaturados. Rev Bras Nutr Clin., v.22, n.3. p.230-236, 2007.

ORSI, R.O.; SFORCIN, J.M.; FUNARI, S.R.C.; GOMES, J.C. Effect of propolis extract on guines pig lung mast cell. Journal of Venomous Animals and Toxins including Tropical Diseases, v.11, n.1, 2005.

PARK, Y.K. et al. Estudo da Preparação dos Extratos de Própolis e suas Aplicações. Ciência e Tecnologia de Alimentos, v.18, n.3, p.313-318, 1998.
PEREIRA, S.A.L; SANTOS, V.M; RODRIGUES, D.M.R; CUNHA-CASTRO, E.C; REIS, M.A; TEIXEIRA, V.P.A. Quantitative analysis of fibrosis and mast cells in the tongue of chronic chagasic patients: autopsy study. Med Mal Infect. v.37, p.229-233, 2007.

RAMOS, A.F.N.; MIRANDA, J.L. Propolis: a review of its anti-inflammatory and healing actions. J. Venom. Anim. Toxins incl. Trop. Dis., v.13, n.4, p.697-710, 2007.

RIBEIRO, M.A.M. Avaliação morfológica, histoquímica e imuno-histoquímica do processo de reparo subcutâneo em ratos submetidos à fotobiomodulação a laser 660nm. Tese de Doutorado, Programa Integrado de Pós-Graduação em Odontologia, Universidade Federal da Bahia, Salvador, Bahia, Brasil, 2006.

RIVERA J.; GILFILLAN A.M. Molecular regulation of mast cell activation. J Allergy Clin Immunol v.117, p.1214-1225, 2006.

SEMENOFF, A.; BOSCO, A.F.; MAIA, D.; RIBEIRO, R.V.; AGUIAR, E.B.H.; ROSCATTO, G.E.G.D.; CIRILO, D.M.; BUZELLE, S.L.; VEDOVE, T.A.D. Influência do aloe vera e própolis na contração de feridas em dorso de ratos. Periodontia. v.17, n.1, p.5-10, 2007.

TRUSHEVA, B.; POPOVA, M.; BANKOVA, V.; SIMOVA, S.; MARCUCCI, M.C.; MIORIN, P.L.; PASIN, F.R.; TSVETKOVA, I. Bioactive constituents of brazilian red propolis. Evid Based Complement Alternat Med, v.3, p.249-254, 2006. 


\section{AGRADECIMENTOS}

Gostaríamos de agradecer ao Conselho Nacional de Pesquisa (CNPq) pelo apoio financeiro a esta pesquisa. versidade Tiradentes, Aracaju, SE.

3 Professor do Programa de Pós-Graduação em Saúde e Ambiente, Universidade Tiradentes, Aracaju, SE.

4 Laboratório de Morfologia e Biologia Estrutural. Instituto de Tecnologia e Pesquisa, Aracaju, SE.

5 Laboratório de Produtos Naturais e Sintéticos. Instituto de Tecnologia e Pesquisa, Aracaju, SE. 